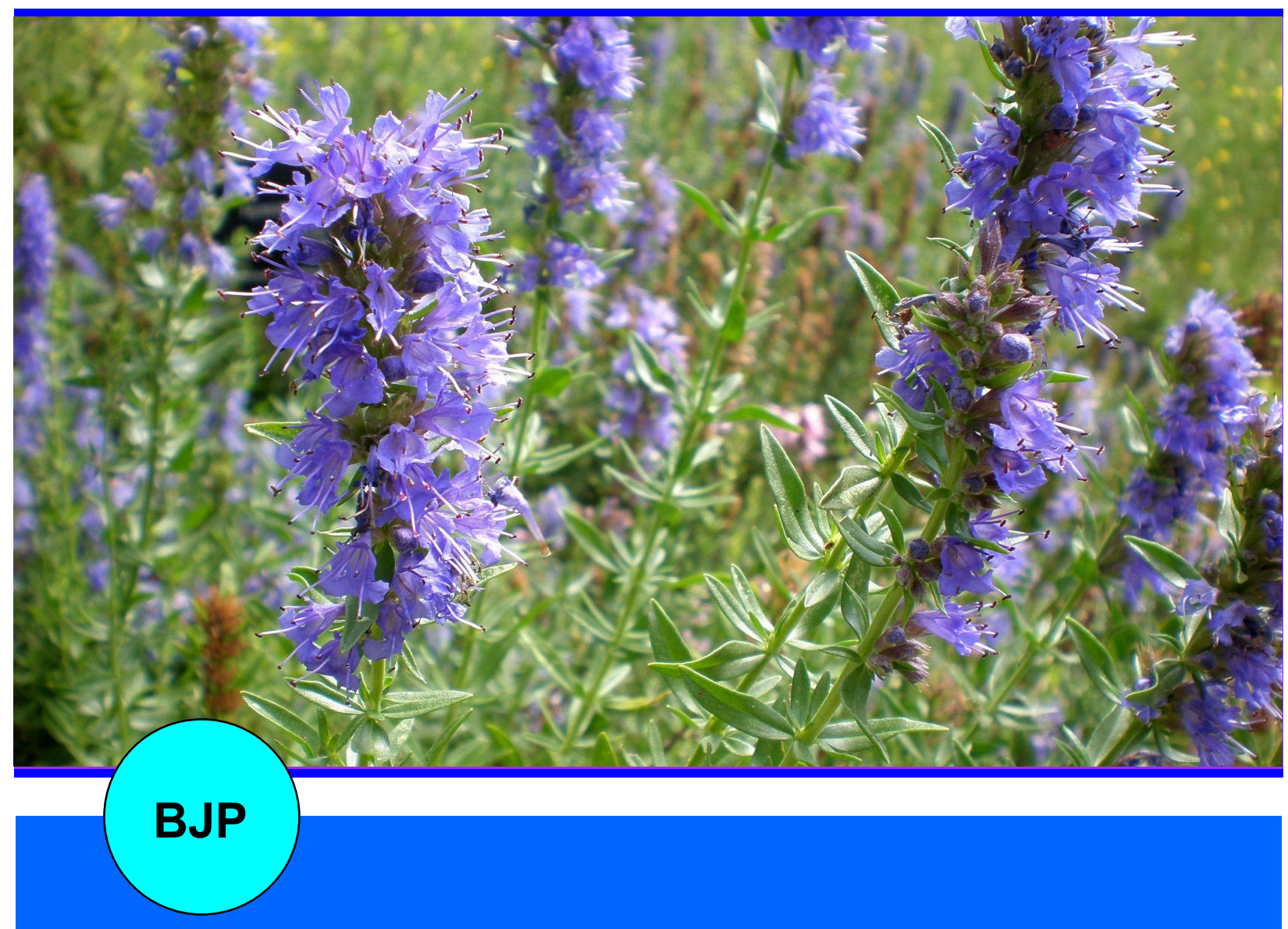

Bangladesh Journal of Pharmacology

Research Article

Effect of Hyssopus officinalis essential oil on chronic stress-induced memory and learning impairment in male mice 
Abstracted/indexed in Academic Search Complete, Asia Journals Online, Bangladesh Journals Online, Biological Abstracts, BIOSIS Previews, CAB Abstracts, Current Abstracts, Directory of Open Access Journals, EMBASE/Excerpta Medica, Google Scholar, HINARI (WHO), International Pharmaceutical Abstracts, Open J-gate, Science Citation Index Expanded, SCOPUS and Social Sciences Citation Index;

ISSN: $1991-0088$

\section{Effect of Hyssopus officinalis essential oil on chronic stress- induced memory and learning impairment in male mice}

\section{Azadeh Salehi and Mahbubeh Setorki}

Department of Biology, Izeh Branch, Islamic Azad University, Izeh, Iran.

\begin{tabular}{|c|c|}
\hline \multicolumn{2}{|l|}{ Article Info } \\
\hline $\begin{array}{l}\text { Received: } \\
\text { Accepted: } \\
\text { Available Online: }\end{array}$ & $\begin{array}{r}16 \text { August } 2017 \\
17 \text { November } 2017 \\
10 \text { December } 2017\end{array}$ \\
\hline \multicolumn{2}{|c|}{ DOI: 10.3329/bjp.v12i4.33585 } \\
\hline \multicolumn{2}{|c|}{$\begin{array}{l}\text { Cite this article: } \\
\text { Salehi A, Setorki M. Effect of Hyssopus } \\
\text { officinalis essential oil on chronic stress } \\
\text {-induced memory and learning im- } \\
\text { pairment in male mice. Bangladesh J } \\
\text { Pharmacol. 2017; 12: 448-54. }\end{array}$} \\
\hline
\end{tabular}

\section{Article Info}

\begin{abstract}
The present study investigated the effect of $H$. officinalis essential oil on avoidance memory in chronic stress-induced. Mice were exposed to chronic immobilization stress and were treated with $H$. officinalis essential oil for 21 days. Memory and learning were measured using shuttle box. The serum levels of corticosterone, malondialdehyde, antioxidant capacity, brain malondialdehyde level and antioxidant capacity were measured. Treatment with $75 \mathrm{mg} / \mathrm{kg}$ of $\mathrm{H}$. officinalis essential oil caused a significant increase in $\mathrm{t} 2$ duration under chronic stress. Serum and brain malondialdehyde levels significantly decreased under stress treated with $75 \mathrm{mg} / \mathrm{kg}$ of $\mathrm{H}$. officinalis essential oil. Brain and serum antioxidant capacity significantly increased under stress treated with $75 \mathrm{mg} / \mathrm{kg}$ of $\mathrm{H}$. officinalis essential oil. The group that received $75 \mathrm{mg} / \mathrm{kg}$ of $H$. officinalis essential oil (inside the restrainer) had insignificantly lower serum corticosterone levels. H. officinalis essential oil has anti-anxiety effects and can promote memory and learning under chronic immobilization stress.
\end{abstract}

\section{Introduction}

Pathological anxiety is one of the common mental disorders in humans whose origin is unknown, including uncertainty, frustration and physiological excitation, and is accompanied by one or more physical problems such as nausea, chest tightness, palpitation, sweating, and headache (Mendlowicz and Stein, 2000).

It was demonstrated that stress and anxiety caused physical and mental diseases, impairment of functioning and coping potential, and ultimately lower quality of life (Mendlowicz and Stein, 2000). In addition, high levels of anxiety are associated with an increased incidence of pulmonary and cardiovascular diseases, and other pathological conditions (Pitsavos et al., 2006). Studies show that dorsal hippocampus plays an important role in controlling anxiety. It is widely associated with the septum, locus coeruleus, hypothalamus, and amygdala all of which are important centers of anxiety control in the brain (Millan, 2003).

A complex network of neurological and endocrine systems causes the response to stress. Glucocorticoids are one of the most important compounds involved in stress, playing an important role in the modulation of memory and cognitive function. Glucocorticoids cause hippocampal atrophy, an important indicator of diseases such as depression and post-traumatic stress (PTS), which are associated with high levels of cortisol. In addition, chronic stress is a major risk factor for Alzheimer's disease, especially in the presence of genetic and environmental factors (Tatomir et al., 2014). The adrenal hormone that is produced due to stress, can affect the hippocampus structure. This has encouraged researchers to investigate the relationship between stress and the hippocampus.

Hippocampus responds quickly to stress because of its 
high concentrations of glucocorticoid receptors (Conrad, 2010). Long-term exposure to stress or glucocorticoids causes many changes in the hippocampal structure, which includes changes in neurochemistry, excitability, neurogenesis, neuronal morphology, and even cell death. These changes are also seen in other hippocampus-related structures especially amygdala (Luine et al., 1994).

Recently, the role of oxidative stress has been demonstrated in the pathogenesis of neurodegenerative and neuropsychiatric diseases such as schizophrenia, depression, and anxiety. High oxygen consumption, high levels of unsaturated fatty acids, and relatively weak anti-oxidant defense system makes the brain highly vulnerable to oxidative stress. Oxidative stress to nucleic acids, proteins, and lipids of the neuronal membrane decreases permeability of the cell membrane, inactivates receptors, enzymes, and ion channels, and damages the neurons (Souza et al., 2007). According to studies, there is a close relationship between the expression of genes involved in anti-oxidant metabolism and anxiety related phenotypes (Hovatta et al., 2005).

In addition, oxidant-rich diets result in obesity, increased the oxidation of proteins and lipids in the frontal cortex, and anxiety-like behavior (Desrumaux et al., 2005). The activation of oxidative stress pathway is another mechanism that should be considered for chronic stress of the brain different areas, which is activated due to increased corticosteroids in the hippocampus, amygdala and prefrontal cortex. Therefore, the use of anti-oxidant compounds can be considered a therapeutic approach. Medicinal plants and their active compounds are rich sources of antioxidant compounds. Although these compounds have other therapeutic mechanisms, alongside their antioxidant effects, for treating certain diseases, they have not attracted much attention despite more convenient access, lower costs, and fewer side effects. The effects of various plants were investigated in preventing and treating the memory deficit or cognitive disorder due to stress.

Hyssopus officinalis L. is an evergreen perennial herb, from family Lamiaceae with four species among which $H$. officinalis is the most important one. The vegetative body of this medicinal plant is used as a drug in most reliable pharmacopeia (Kreis et al., 1990). H. officinalis is used to treat viral infections such as common cold, sore throats, bronchitis, and asthma (Fathiazad and Hamedeyazdan, 2011). It contains anti-inflammatory and antispasmodic agents and is effective to treat hypertension and diabetes.

In addition to having pharmaceutical usages, $H$. officenalis extract and essential oil are used in various foods such as sauce, liqueurs and spicy spices (Najafpournavayi and Mirza, 2003). Research has shown that $H$. officinalis essential oil has antibacterial and anti-fungal effects (Dehghanzadeh et al., 2012). The essential oil concentration of $H$. officinalis vegetative body was reported to be $0.03-1$ and $0.1-1.8 \%$ (Dzhumaev, 1981) Pinocamphone (50\%), alpha- and beta-pinene, camphene, and sesquiterpene alcohols are the most important compounds of $H$. officinalis essential oil. Besides that, its compounds body contains flavonoids, tannins (5-8\%), bitter substances (3-6\%), and other compounds such as dioxin, hyspin, and mucilaginous compounds (Dehghanzadeh et al., 2012).

The purpose of this study was to investigate the effect of $H$. officinalis essential oil on chronic stress-induced memory and learning impairments in male mice.

\section{Materials and Methods}

\section{Preparation of the H. officinalis essential oil}

To extract the essential oil, clavenger that works with water distillation was used. A pulverized $H$. officinalis sample of $142 \mathrm{~g}$ was weighed using an analytical scale, and transferred to a 3L balloon connected to the clavenger. $1500 \mathrm{~mL}$ distilled water was added to balloon containing pulverized $H$. officinalis. Extraction was conducted within 4 hours and the essential oil was collected and dehydrated using water-free sodium sulfate. The resulting essential oil was stored at $-20^{\circ} \mathrm{C}$ temperature in a freezer until it was introduced into a GC/MS kit.

\section{Animal tests}

Laboratory animals

Ninety adult male BALB/c mice (weighing 20-30 g) were selected and maintained under 12 hours light/ darkness at appropriate $25^{\circ} \mathrm{C}$ temperature with free access to the same water and food. All experiments were performed in accordance with the Guide for the Care and Use of Laboratory Animals

\section{Chronic stress model}

To induce chronic stress, the mice were placed in a restrainer for 6 consecutive hours a day. The restrainer contained pores so that the mice could breathe easily. During this period, the mice fasted. This procedure continued for 21 days. Meanwhile, a control group was fasted for 6 hours (Xu et al., 2009).

\section{Animal groups}

Group 1 (control 1): Mice under the restrainer-induced immobilization stress for 6 consecutive hours a day and intraperitoneally treated with normal saline for 21 days; Group 2 (control 2): Mice fasted (without apparatus) for 6 consecutive hours a day and intraperitoneally treated with normal saline for 21 days; Group 3 (control 3): Healthy mice intraperitoneally receiving normal saline 
alone (no apparatus) for 21 days; Groups 4-6 (treatment groups): Mice under restrainer- induced immobilization stress for 6 consecutive hours a day and intraperitoneally treated with $H$. officinalis essential oil $(25,50$ and $75 \mathrm{mg} / \mathrm{kg}$ ) for 21 days; Groups 7-9 (control): Healthy mice intraperitoneally treated with $H$. officinalis essential oil $(25,50$ and $75 \mathrm{mg} / \mathrm{kg})$ for 21 days. All groups were compared to control 1.

\section{Avoidance memory (shuttle box) test}

This apparatus consists of an electric shocker, a bright chamber, a dark chamber, and a 15-watt bulb. Its floor is made-up of a conductive metal grid and the two chambers are connected via a guillotine door. This fearbased test was performed within four consecutive days.

The 1st and 2nd days were specified to training the mouse and adapting them to the apparatus. On the first day, the mouse was left in the bright chamber for 5 min, then the sliding door between the light and dark chambers was opened, and the mouse entered the dark chamber voluntarily, remained there for $5 \mathrm{~min}$, and finally left it.

The procedure of the 2nd day was the same as that of the first day. When the mouse was left in the bright chamber on the third day, the guillotine door between the two chambers was removed $20 \mathrm{sec}$ later and latency to enter the dark chamber was recorded and considered initial latency (t1).

The mice entered the dark chamber, and an electrical shock $(1 \mathrm{~mA} / \mathrm{sec})$ was exerted to the mice so that they only paddled, and left the apparatus. In this test, latency to enter the dark chamber was considered initial latency.

The mouse remained in the bright chamber on the 4th day, and while turning the lamp on and opening the door, interval between being placed in the bright chamber and entering the dark chamber was measured (up to $300 \mathrm{sec}$ ) and considered delay through passing (t2) (Rabiei et al., 2015).

\section{Serum and brain anti-oxidant capacity}

Once the behavioral test was completed, the mice were anesthetized, heart blood samples were taken, and heart and the brain tissues were removed. Ferric reducing ability of powder is based on the ability of the serum to restore ferric ions in the presence of tripyridyls-triazine, and the respective absorbance is recorded spectrophotometrically (Rabiei et al., 2015).

\section{Measuring serum malondialdehyde level}

In brief, $0.5 \mathrm{~g}$ of thiobarbituric acid was mixed with 80 $\mathrm{mL}$ of acetic acid $20 \%$ whose $\mathrm{pH}$ was set at 3.5 by adding sodium hydroxide and its volume was diluted using $100 \mathrm{~mL}$ acetic acid $20 \% .100 \mu \mathrm{L}$ of serum sample was mixed with $100 \mu \mathrm{L}$ of sodium dodecyle sulfate solution $8.1 \%$ and $2.5 \mathrm{~mL}$ of stock solution. The samples were placed in water bath bain marie for 1 hour, then cooled and centrifuged at 4,000 rpm. The optical absorbance of the supernatant was read at $523 \mathrm{~nm}$ wavelength (Rabiei et al., 2014).

\section{Measuring brain malondialdehyde level}

One gram of the brain tissue was homogenized in cooled $\mathrm{KCl} 2.5 \%$ at 1:10 (weight-volume) and incubated in a metabolic incubator shaker at $(37 \pm 1)^{\circ} \mathrm{C}$ for $60 \mathrm{~min}$. Then, $1 \mathrm{~mL}$ tetrachloroacetic acid $5 \%$ and $1 \mathrm{~mL}$ thiobarbituric acid $67 \%$ were added and mixed thoroughly. The solution of each vial was transferred to a centrifugation tube and centrifuged at $2000 \mathrm{rpm}$ for $15 \mathrm{~min}$. Then, the supernatant was transferred to another tube and placed in the water bath (bain marie). Ten minutes later, the test tubes were cooled and absorbance was read at $535 \mathrm{~nm}$ wavelength (Rabiei et al., 2014).

\section{Measuring serum corticosterone levels}

After the behavioral test was completed, the mice were anesthetized and heart blood samples were taken and serum was separated. A specific kit was used to measure corticosterone levels by colorimetric method using spectrophotometer according to the manufacturer's instructions. Results were reported in $\mathrm{ng} / \mathrm{mL}$.

\section{Statistical analysis}

Data analysis was conducted by SPSS 16. First, Kolmogorov-Smirnov test was used to investigate the normality of the data distribution and Levene's test was used to investigate the homogeneity of variances one-way analysis of variance and Tukey's test were used to investigate the significance of difference among different treatments and their respective mean values, respectively. Data were expressed as mean \pm standard error, and $\mathrm{p}<0.05$ was considered the level of statistical significance.

\section{Results}

\section{Initial and secondary latency in shuttle box}

In the shuttle box, there was no significant difference in initial latency to enter the dark chamber (t1) among the groups. But group treated with $75 \mathrm{mg} / \mathrm{kg}$ dose of the essential oil and inside the restrainer had a longer $\mathrm{t} 2$ (the secondary latency) than the control Group 1 (Figure 1). Control Group 3 had a longer t 2 than the control Group 1. Groups that received 25 and $75 \mathrm{mg} / \mathrm{kg}$ of the essential oil and were not inside the restrainer had longer 2 than the control Group 1.

\section{Serum anti-oxidant capacity}

Serum anti-oxidant capacity in $75 \mathrm{mg} / \mathrm{kg}$ of the essen- 


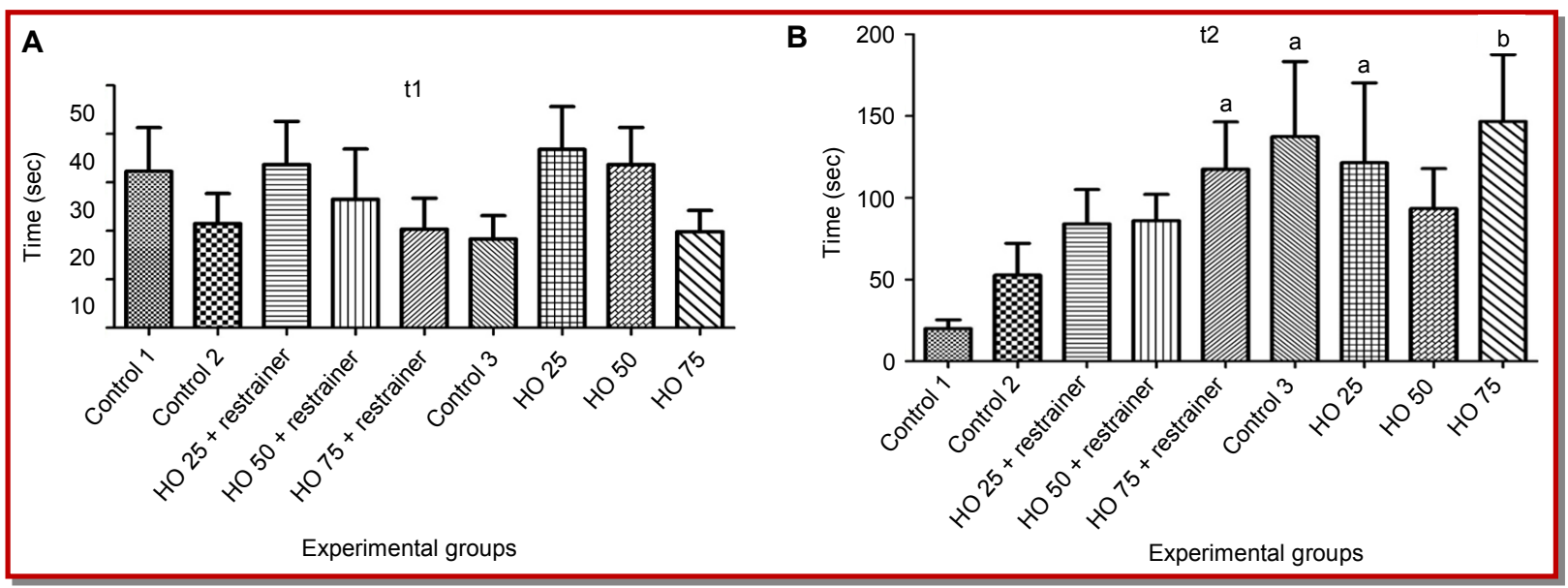

Figure 1: Duration of initial (A) and secondary (B) latency in passive avoidance memory test. All groups are compared with control group 1. aSignificant difference compared to control Group $1(\mathrm{p}<0.05)$; b significant difference compared to control Group 1 $(\mathrm{p}<0.01)$; HO: Hyssopus officinalis

tial oil-receiving group and inside the restrainer, was significantly higher than the control Group 1 (Figure 2). In the control Group 3, serum anti-oxidant capacity was higher than the control Group 1. Groups that received the 50 and $75 \mathrm{mg} / \mathrm{kg}$ of $\mathrm{H}$. officinalis essential oil and were not inside the restrainer had a significantly higher anti-oxidant capacity compared with the control Group 1.

\section{Brain anti-oxidant capacity}

Brain anti-oxidant capacity in hyssop (50 and $75 \mathrm{mg}$ ) receiving groups, which were inside retainer, was significantly higher than control group 1 (Figure 2). Brain anti-oxidant capacity was higher in control group 3 than control group 1. Groups that received the $75 \mathrm{mg} /$ $\mathrm{kg}$ of $\mathrm{H}$. officinalis essential oil and was not inside the res-trainer had a significantly higher brain anti-oxidant capacity compared to the control Group 1. There was no significant difference between control Groups 1 and 2.

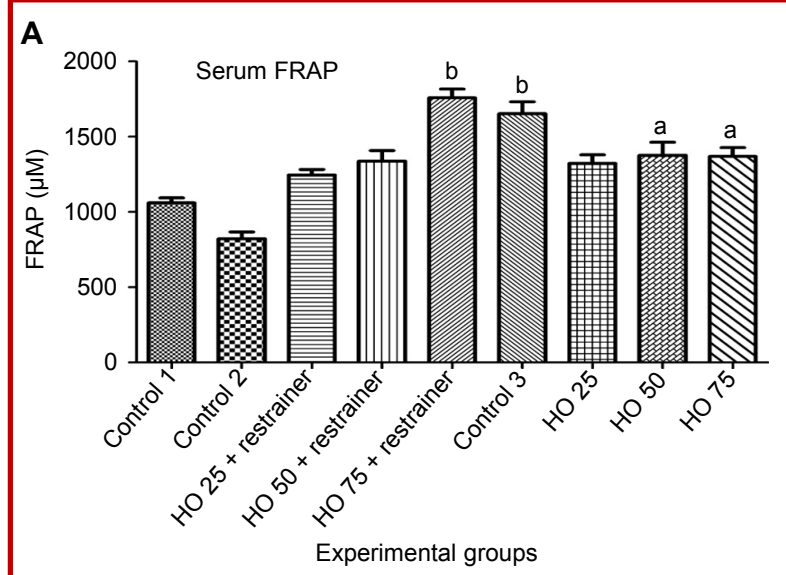

\section{Serum malondialdehyde levels}

In group that received $75 \mathrm{mg} / \mathrm{kg} \mathrm{H}$. officinalis essential oil and was inside the restrainer, serum malondialdehyde level significantly decreased compared to the control Group 1 (the control group inside the restrainer) (Figure 3). There was no significant difference between Groups 1 and 2 (control outside the restrainer and fasted). Control Group 3 (control receiving normal saline alone and that was not inside the restrainer but had access to water and food) had lower serum malondialdehyde levels than the control Group 1.

Group that received $75 \mathrm{mg} / \mathrm{kg}$ of $H$. officinalis essential oil and was not inside the restrainer had a significantly lower serum malondialdehyde level than the control Group 1.

\section{Brain malondialdehyde level}

Brain malondialdehyde level was significantly higher in the control Group 2 than the control Group 1.

\section{B}

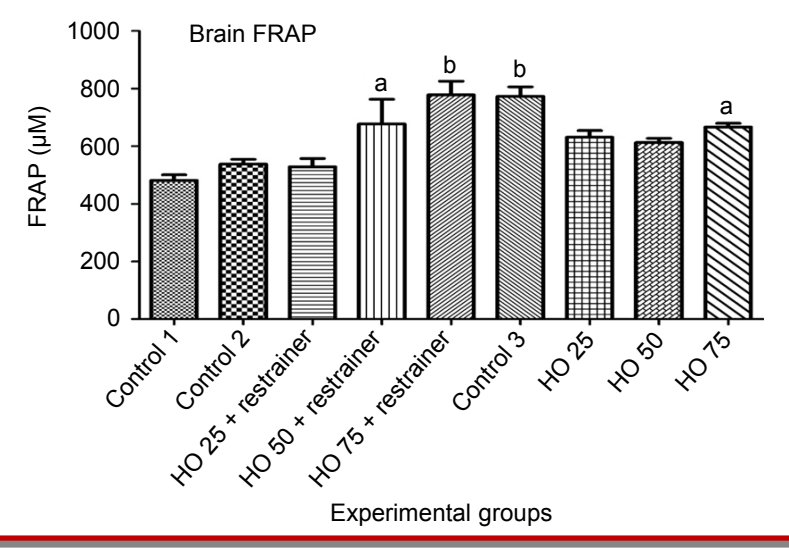

Figure 2: Serum (A) and brain (B) anti-oxidant capacity in different groups; all groups are compared with control Group 1. aSignif-

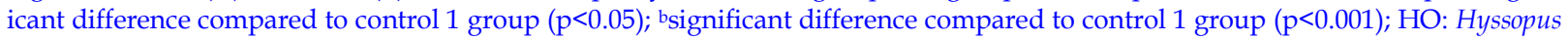
officinalis 


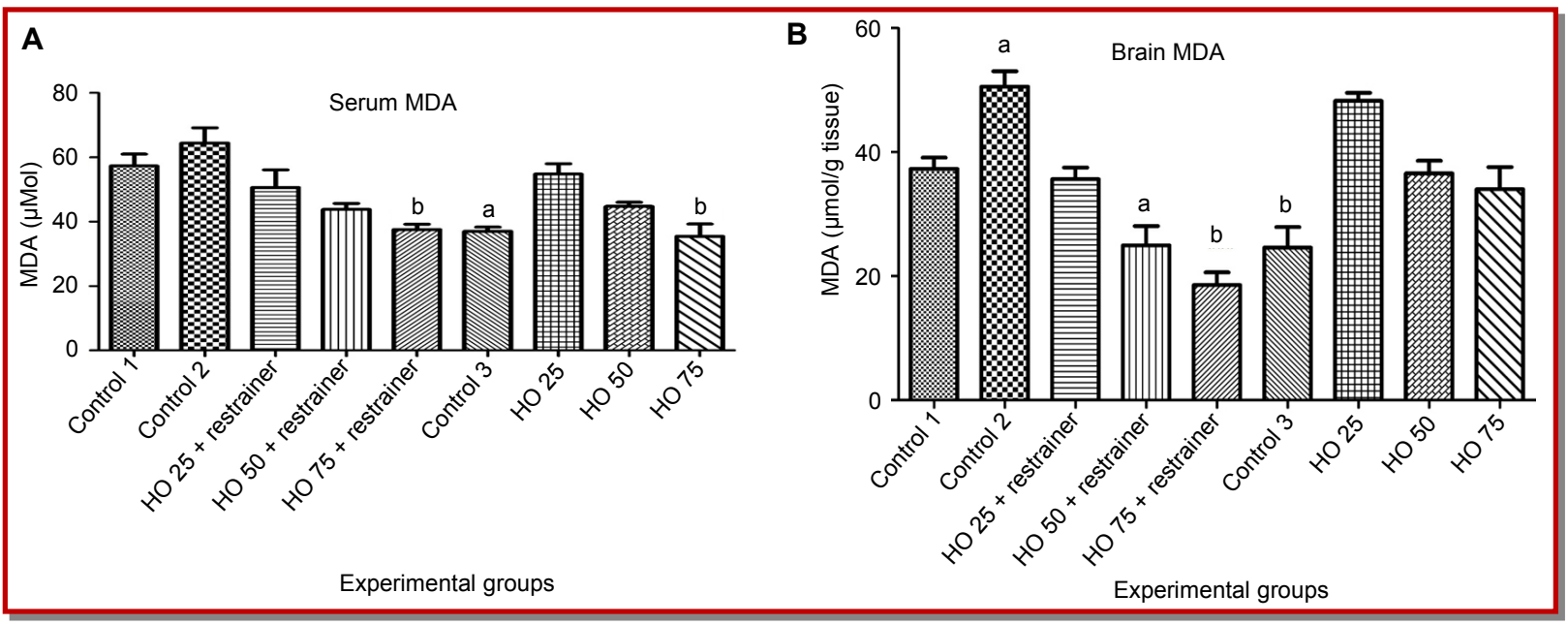

Figure 3: Serum (A) and brain (B) malondialdehyde levels in different groups; all groups are compared with control group 1. aSignificant difference compared to control 1 group ( $\mathrm{p}<0.01$ ); bsignificant difference compared to control 1 group ( $\mathrm{p}<0.001)$; HO: Hyssopus officinalis

Brain MDA levels were significantly lower in 50 and 75 $\mathrm{mg} / \mathrm{kg}$ of $H$. officinalis receiving groups (in the restrainer) than the control Group 1. The control Group 3 had significantly lower brain malondialdehyde level than the control Group 1.

\section{Serum corticosterone levels}

The results of the effect of $H$. officinalis essential oil on serum corticosterone in different groups are shown in Figure 4 . The serum corticosterone levels were significantly higher in group under the restrainer-induced chronic stress (control 1) than the control Group 3 $(\mathrm{p}<0.05)$. The group that received $75 \mathrm{mg} / \mathrm{kg}$ of $H$. officinalis essential oil (inside the restrainer) had in significantly lower serum corticosterone levels than the control Group 1.

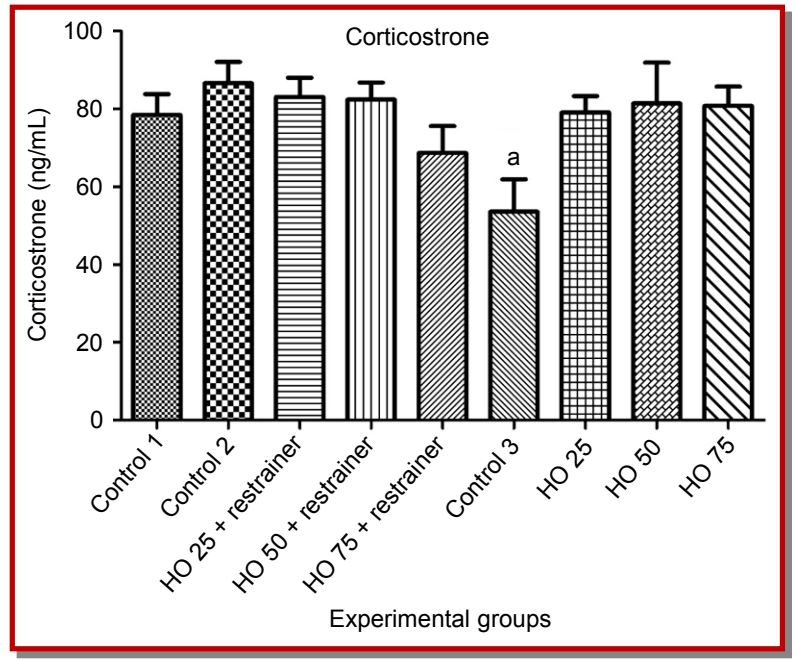

Figure 4: The effect of intraperitoneal injection of different doses of Hyssopus officinalis essential oil on serum corticosterone levels; all groups are compared with control group 1; asignificant difference compared to control 1 group $(\mathrm{p}<0.05)$; HO: Hyssopus officinalis

\section{Discussion}

The present study was conducted to investigate the effects of $H$. officinalis essential oil on learning and memory in mice under chronic stress. The results showed that chronic restraint stress induced by the restrainer for 21 days caused learning and memory impairment in the shuttle box.

Our results are consistent with previous studies, showing that chronic stress disrupts memory and learning (McLaughlin et al., 2007; Srikumar et al., 2006). Chronic stress causes a change in the number and shape of the hippocampal dendritic spines, cell loss, reduction of neurogenesis in the dentate gyrus, reduction of brain -derived neurotrophic factor expression, impairment of prolonged strengthening in the hippocampal synapses, and changes in the levels of neurotransmitters (Karkada et al., 2012).

Interestingly, chronic treatment with $H$. officinalis essential oil for 21 days improved learning and memory impairment induced by chronic stress. Although the precise mechanism is still unknown, $H$. officinalis beneficial effects on chronic stress-induced cognitive disorders can be due to its anti-oxidant and neuroprotective effects.

Soleimani et al. study demonstrated the anti-oxidant effects of $H$. officinalis in 1,1-diphenyl 1,1 picrylhydrazyl, 2,2 azinobis test (ABTS), and beta-carotene tests; this plant has potent anti-oxidant effects (Soleimani et al., 2011) In addition, the results of this study indicated that treatment with $H$. officinalis essential oil for 21 days caused a significant increase in serum and brain tissue anti-oxidant levels and decrease in serum and brain tissue malondialdehyde levels in mice under chronic stress, which is a marker of oxidative stress.

It has been reported that there is a significant relation- 
ship between oxidative stress markers and anxiety-related phenotypes. The expressions of glutathione reductase- 1 and glyoxalase-1, mice in the brain of anxious mice which are involved in the anti-oxidant defense system, have a significant correlation with anxietyrelated phenotypes (Hovatta et al., 2005).

In addition, it was reported that the deficiency of endogenous anti-oxidants in the mice brain significantly increased the levels of central oxidative stress markers and therefore, led to anxious behaviors (Desrumaux et al., 2005).

The consumption of pro-oxidant-rich diet increases the oxidation of proteins and fats in the brain frontal lobe and results in anxiety-like behavior (Souza et al., 2007)

Liu et al. (1996) showed that anxiety induced by the mobility restriction caused significant increase in oxidation of lipids and proteins in the cerebral cortex, hypothalamus, lumbar spine, and the medulla oblongata. Besides that, mobility restriction- induced anxiety significantly reduced the activity of anti-oxidant enzymes and the oxidative damage of DNA in neuronal brain (Liu et al., 1996).

Based on the results of GC-MS on $H$. officinalis, its essential oil contains $19.76 \% \beta$-pinene, $2.11 \%$ limonene, $7.16 \%$ eucalyptol, $3.56 \%$ methane, $23.84 \%$ berbenone, $17.95 \%$ pinocamphone, and $3.11 \%$ Linalool (Said-Al et al., 2015).

A study investigated the sedative and anti-depressant effects of eucalyptol, $\beta$-pinene, and limonene in various behavioral models separately, and the results indicated that $\beta$-pinene had significant anti-depressant and sedative effects (Guzmán-Gutiérrez et al., 2012). Another study has reported that $\beta$-pinene binds to the active site of the $\mathrm{GABA}_{\mathrm{A}}$ receptor and increases the binding of GABA to the receptor (Aoshima and Hamamoto, 1999).

The GABAergic system is considered the first therapeutic approach to cope with anxiety because of its known inhibitory effects on the central nervous system, as well as rapid mediation in coping with anxiety. The widespread distribution of GABA receptors in different regions of the brain (hippocampus, parahippocampus and orbitofrontal cortex) may be responsible for their rapid sedation during activation (Crestani et al., 1999).

It was reported that the activity of GABA reduced in the forehead, temporal, occipital, and hippocampal cortex in patients with anxiety disorders (Bremner et al., 2000) and treatment with benzodiazepines increases GABA neurotransmitter activity (Sacerdote et al., 1999).

Given the sedative and anti-anxiety effects of $H$. officinalis essential oil, it can be argued that this essential oil improves the anti-anxiety and sedative effects by increasing the GABA neurotransmitter levels. However, it is recommended to investigate this issue using GABA antagonists and determination of GABA receptor expression.

Studies have shown that chronic and acute stress are associated with the neuroendocrine disorders. In a study on mice showed that exposure to chronic stress for 21 days developed neuroendocrine disorder and their serum adrenocorticotropin and corticosterone levels increased significantly (Schaalan and Nassar, 2011).

The acute ( 2 and 6 hours) and chronic $(6,12$, and 24 days) immobilization-induced stress caused the significant increase in serum corticosterone levels in mice (Tinnikov, 1999).

In the present study, $H$. officinalis essential oil reduced serum corticosterone level yet insignificantly, and it seems that other mechanisms have more prominent roles in exerting sedative effects and improving memory and learning.

\section{Conclusion}

The treatment of mice with $H$. officinalis essential oil improved memory and learning in the shuttle box and reduced the malondialdehyde level, which is a marker of oxida-tive stress, in mice under chronic stress. These effects can be due to the anti-oxidant and neuroprotective properties of this medicinal plant.

\section{Conflict of Interest}

The authors declare that there is no conflict of interest.

\section{Acknowledgement}

The authors thanks to the Laboratory Islamic Azad University Izeh. This article has been derived from a MSc thesis.

\section{References}

Aoshima H, Hamamoto K. Potentiation of GABAA receptors expressed in Xenopus oocytes by perfume and phytoncid. Biosci Biotechnol Biochem. 1999; 63: 743-48.

Bremner JD, Innis RB, White $\mathrm{T}$, Fujita $\mathrm{M}$, Silbersweig D, Goddard AW, Staib L, Stern E, Cappiello A, Woods S, Baldwin R, Charney DS. SPECT [I-123] iomazenil measurement of the benzodiazepine receptor in panic disorder. Biol Psychiatry. 2000; 47: 96-106.

Conrad CD. A critical review of chronic stress effects on spatial learning and memory. Prog Neuro-Psychopharmacol Biol Psychiatry. 2010; 34: 742-55.

Crestani F,Lorez M, Bear K, Essrich C, Benek D, Laurent JP, Belzung C,Fritschy JM, Luscher B, Mohler H. Decreased GABAA-receptor clustering results in enhanced anxiety and a bias for threat cues. Nat Neurosci. 1999; 2: 833-39. 
Dehghanzadeh N, Ketabchi S, Alizadeh A. Essential oil composition and antibacterial activity of Hyssopus officinalis L. grown in Iran. Asian J Biol Sci. 2012; 3: 767-71.

Desrumaux C, Risold PY, Schroeder H, Deckert V, Masson D, Athias A, Laplanche H, Le Guern N, Blache D, Jiang XC, Tall AR, Desor D, Lagrost L. Phospholipid transfer protein (PLTP) deficiency reduces brain vitamin E content and increases anxiety in mice. FASEB J. 2005; 19: 296-97.

Dzhumaev K. Dynamics of essential oil accumulation in Hyssopus zeravschanicus. Uzbekskii Biologicheskii Zhurnal. 1981.

Fathiazad F, Hamedeyazdan S. A review on Hyssopus officinalis L: Composition and biological activities. Academ J. 2011.

Guzmán-Gutiérrez S, Gómez-Cansino R, García-Zebadúa J, Jiménez-Pérez N, Reyes-Chilpa R. Antidepressant activity of Litsea glaucescens essential oil: Identification of $\beta$-pinene and linalool as active principles. J Ethnopharmacol. 2012; 143: 673 -79 .

Hovatta I, Tennant RS, Helton R, Marr RA, Singer O, Redwine $\mathrm{JM}$, et al. Glyoxalase 1 and glutathione reductase 1 regulate anxiety in mice. Nature 2005; 438: 662-66.

Karkada G, Shenoy K, Halahalli H, Karanth K. Nardostachys jatamansi extract prevents chronic restraint stress-induced learning and memory deficits in a radial arm maze task. J Nat Sci Biol Med. 2012; 3: 125.

Kreis W, Kaplan MH, Freeman J, Sun DK, Sarin PS. Inhibition of HIV replication by Hyssop officinalis extracts. Antiviral Res. 1990; 14: 323-37.

Liu J, Wang X, Shigenaga M, Yeo H, Mori A, Ames B. Immobilization stress causes oxidative damage to lipid, protein, and DNA in the brain of rats. FASEB J. 1996; 10: 1532-38.

Luine V, Villegas M, Martinez C, McEwen BS. Repeated stress causes reversible impairments of spatial memory performance. Brain Res. 1994; 639: 167-70.

McLaughlin KJ, Gomez JL, Baran SE, Conrad CD. The effects of chronic stress on hippocampal morphology and function: An evaluation of chronic restraint paradigms. Brain Res. 2007; 1161: 56-64.

Mendlowicz MV, Stein MB. Quality of life in individuals with anxiety disorders. Am J Psychiatry. 2000; 157: 669-82.

Millan MJ. The neurobiology and control of anxious states. Progress Neurobiol. 2003; 70: 83-244.

Najafpour-navayi M, Mirza M. Comparision of chemical components of Hyssopus officinalis L. essential oil in vitro and in natural habitat. Iranian J Med Aromatic Plants. 2003; 18:
41-53.

Pitsavos C, Panagiotakos DB, Papageorgiou C, Tsetsekou E, Soldatos C, Stefanadis C. Anxiety in relation to inflammation and coagulation markers, among healthy adults: The ATTICA study. Atherosclerosis 2006; 185: 320-26.

Rabiei Z, Mokhtari S, Asgharzade S, Gholami M, Rahnama S, Rafieian-kopaei M. Inhibitory effect of thymus vulgaris extract on memory impairment induced by scopolamine in rat. Asian Pacific J Trop Biomed. 2015; 5: 845-51.

Rabiei Z, Rafieian-kopaei M, Heidarian E, Saghaei E, Mokhtari S. Effects of Zizyphus jujube extract on memory and learning impairment induced by bilateral electric lesions of the nucleus basalis of meynert in rat. Neurochem Res. 2014; 39: 353-60.

Sacerdote P, Panerai A, Frattola L, Ferrarese C. Benzodiazepine-induced chemotaxis is impaired in monocytes from patients with generalized anxiety disorder. Psychoneuroendocrinology. 1999; 24: 243-49.

Said-Al Ahl HA, Abbas ZK, Sabra AS, Tkachenko KG. Essential oil composition of Hyssopus officinalis L. cultivated in Egypt. Int J Plant Sci Ecol. 2015; 1: 49-53.

Schaalan MF, Nassar NN. Effects of octreotide in chronically mild stressed rats: Possible role of immune and oxidative stress pathways. Neurochem Res. 2011; 36: 1717.

Soleimani H, Barzegar M, Sahari M, Naghdi Badi H. An investigation on the anti-oxidant activities of Hyssopus officinalis L. and Echinacea purpurea L. plant extracts in oil model system. J Med Plant. 2011; 1: 61-72.

Souza CG, Moreira JD, Siqueira IR, Pereira AG, Rieger DK, Souza DO, Souza TM, Portela LV, Perry ML. Highly palatable diet consumption increases protein oxidation in rat frontal cortex and anxiety-like behavior. Life Sci. 2007; 81: 198-203.

Srikumar B, Raju T, Rao BS. The involvement of cholinergic and noradrenergic systems in behavioral recovery following oxotremorine treatment to chronically stressed rats. Neuroscience 2006; 143: 679-88.

Tatomir A, Micu C, Crivii C. The impact of stress and glucocorticoids on memory. Clujul Med. 2014; 87: 3.

Tinnikov AA. Responses of serum corticosterone and corticesteroid-binding globulin to acute and prolonged stress in the rat. Endocrine 1999; 11: 145-50.

Xu Y, Lin D, Li S, Li G, Shyamala SG, Barish PA, Vernon MM, Pan J, Ogle WO. Curcumin reverses impaired cognition and neuronal plasticity induced by chronic stress. Neuropharmacology 2009; 57: 463-71. 